\title{
Era Penyiaran Digital: Pengembangan atau Pemberangusan TV Lokal dan TV Komunitas?
}

\author{
Agung Prabowo \\ Dosen Ilmu Komunikasi - UPN Veteran Yogyakarta
}

\begin{abstract}
Abstrak
Migrasi TV digital masih menyimpan banyak pertanyaan yang belum ditemukan jawabannya. Perkembangan terakhir Lembaga Penyiaran Penyelenggara Penyiaran Multipleksing (LP3M) di 7 zona sudah ditetapkan. Masih tersisa 8 zona yang lain. Pemenang penyelenggara multipleksing adalah pelaku broadcasting yang saat ini menguasai pertelevisian di Indonesia. Investasi membangun multipleksing yang akan berfungsi memancarkan sinyal digital ini merupakan kunci dalam bisnis TV digital. Semua broadcaster harus menyewa untuk bisa siaran. Hal inilah yang menimbulkan masalah bagi TV lokal maupun komunitas. Untuk menyewa mux (multipleksing) angkanya diperkirakan 40 juta per bulan. Belum lagi mereka harus berinvestasi peralatan untuk program yang berbasis digital. Untuk permasalahan ini diperlukan campur tangan pemerintah. Harus ada regulasi yang melindungi pelaku yang lemah dari sisi permodalan, namun memiliki keberpihakan kepada masyarakat seperti TV komunitas.
\end{abstract}

Kata kunci : TV digital, TV analog, TV komunitas, TV lokal, set top box

\begin{abstract}
Digital TV migration still save a lot of questions that have not found the answer. Recent developments The Institution of Broadcasting Services Multiplexing (LP3M) in 7 zones have been established. Remaining 8 other zones. Winners multiplexing organizers are actors who currently control the broadcasting of television in Indonesia. Investments that will build multiplexing function emits a digital signal is a key in the digital TV business. All broadcasters must hire to be broadcast. This has caused problems for local and community TV. For rent mux (multiplexing) estimated the figure of 40 million per month. Not to mention they have to invest in equipment for digital-based programs. For this problem required government intervention. There should be regulations that protect the weak actors from the capital side, but has a bias to the community such as community TV.
\end{abstract}

Key words : digital television, analog television, community television, local television, set top box

\section{Pendahuluan}

Perubahan device teknologi komunikasi sangat bervariasi dan berlangsung dalam waktu yang cepat. Industri "hilir" dalam teknologi komunikasi ini mempengaruhi industri lain yang berkaitan, termasuk industri penyiaran. Inovasi ini juga merupakan salah satu faktor kuat yang mendorong perubahan teknologi penyiaran dari analog ke digital. Apabila masa sebelumnya pesawat penerima siaran hanya melalui fix television (TV yang ada di rumah), sekarang dengan ditemukannya tablet dan smartphone. Akibatnya aktivitas menonton televisi bisa dilakukan di mana saja. Perilaku menonton TV pun mulai berubah. Ratarata menonton $\mathrm{TV}$ di rumah hanya 
sekitar 2,5 jam. Selebihnya aktivitas yang berhubungan dengan media dilakukan melalui tablet maupun smartphone.

Melihat perubahan teknologi serta perilaku konsumsi media itulah mendorong pemerintah mengeluarkan kebijakan migrasi penyiaran analog ke digital. Hingga Agustus 2012, langkah pemerintah untuk memasuki era penyiaran digital, dilakukan melalui Peraturan Menteri Kominfo No. 05 tahun 2012 dengan mengadopsi standar penyiaran televisi digital terestrial Digital Video Broadcasting Terrestrial second generation (DVB-T2). Sebelumnya, melalui Keputusan Menteri Komunikasi dan Informatika Nomor: 07/P/ M.KOMINFO/3/2007 tanggal 21 Maret 2007 tentang Standar Penyiaran Digital Terestrial untuk Televisi Tidak Bergerak di Indonesia, pemerintah menetapkan standar DVB-T (Digital Video Broadcating-Teresterial) sebagai standar penyiaran televisi digital teresterial tidak bergerak di Indonesia.

Keunggulan DVB-T2 dibanding DVB-T atau teknologi digital terrestrial television (DTT) yang lain di antaranya adalah sinyal yang lebih kuat sehingga bisa diterima oleh antena in door maupun out door. Bisa digunakan untuk siaran berkualitas Standard Definition TV, High Definition TV (HDTV), mobile TV secara bersamaan, coverage-nya lebih luas, power device reciever-nya lebih hemat dan sebagainya. Teknologi DVB-T2 ini memungkinkan munculnya era konvergensi TV. Namun untuk memasuki era konvergensi TV perlu perubahan budaya mengkonsumsi media.

Dilihat dari sifat penggunaannya, jenis penyiaran sebenarnya ada empat. Pertama, TV Tradisonal, yaitu penyiaran televisi yang seperti dikonsumsi saat ini. Televisi hanya ditonton tanpa variasi aktivitas yang lain. Kedua Hibryd TV, yaitu siaran yang bersamaan antara TV dan internet. Internet diharapkan akan bisa bridging dengan TV. Perilaku masyarakat dalam mengkonsumsi TV dan internet berbeda. Mereka Mengkonsumsi internet bisa enam jam lebih. Sementara nonton TV hanya berkisar satu jam saja. Penyiaran hibryd dilakukan Untuk memenuhi perilaku yang seperti ini, sehingga mereka yang sedang main internet bisa juga melakukan aktivitas menonton TV. Ketiga TV Interaktif yaitu penyiaran yang tidak hanya satu arah, tetapi bisa digunakan dua arah. Penonton TV bisa melakukan interaksi dengan program yang sedang ditonton. Keempat TV Konvergensi, yaitu penyiaran konvergensi tidak hanya berbasis internet tetapi juga berbasis IT platform lain seperti misalnya di smart phone, mobil. Penyiaran ini akan mampu menyesuaikan adanya berbagai macam device yang ada di masyarakat untuk menerima siaran TV, termasuk mobile TV. Saat ini sepertinya masyarakat Indonesia masih berada pada TV Tradisional.

Gambar 1.

Sifat Teknologi Penyiaran

\begin{tabular}{|c|c|c|}
\hline & Single Platform & Multi Platform \\
\hline One Way & Traditional TV & Hybrid TV \\
\hline Two Way & Interactive TV & Media Convergence \\
\hline
\end{tabular}


Sementara sesuai dengan saluran yang digunakan, teknologi penyiaran digital dapat digolongkan ke dalam tiga jenis, yaitu penyiaran digital melalui satelit, penyiaran digital melalui kabel optik dan penyiaran melalui frekuensi radio (terestrial). Dilihat dari potensi teknologinya, penyiaran melalui kabel optik sebenarnya lebih unggul dibanding yang lain, karena teknologi ini memungkinkan adanya menu interaktif. Namun apabila saat ini yang menjadi topik diskusi yang hangat adalah penyiaran terestrial, hal ini tidak terlepas dari sifat frekuensi ini yang merupakan domain publik. Wilayah publik inilah yang menjadi alasan harus adanya aturan main serta kebijakan yang dapat menjaga kepentingan publik selain kekuatannya dalam membentuk masyarakat informasi. Sifat publik ini juga menjadikan proses migrasi penyiaran tidak bisa berjalan mulus sesuai dengan tahapan yang sudah ditetapkan.

Ketidakmulusan tahapan sesuai yang sudah ditetapkan terlihat dari realisasi yang terjadi hingga pertengahan tahun 2013 ini. Sesuai dengan roadmap migrasi penyiaran digital, pada tahun 2012 mestinya swich off sudah dimulai di DKI Jakarta dan daerah ekonomi maju seperti Jawa Barat, Jawa Tengah dan Jawa Timur. Langkah pelelangan Lembaga Penyiaran Penyelenggara Penyiaran Multipleksing (LP3M) sudah dilakukan. Pemenang LP3M sudah ditetapkan. Hardiyanto Saroso, sekretaris perusahaan SCTV yang menjadi salah satu LP3M yang memenangkan di zona DKI dan Jawa Timur mengaku bahwa pihaknya sudah menyiapkan perangkat pemancar digital (multyplexer) sejak uji coba 2008 dan sudah bersiaran rutin sejak September 2012. Namun karena belum ada kesiapan perangkat pendukung yang lainnya seperti receiver (Set Top Box) maka siaran ini belum banyak diketahui oleh masyarakat. Kondisi ini menimbulkan dilema di pihak LP3M. Perangkat pemancar digital yang memakan investasi tidak sedikit (konon hingga 400 Milyar Rupiah) belum bisa dimanfaatkan secara optimal. Untuk menjaga dari ancaman kerusakan, biaya pemeliharaan pemancar inipun tidak sedikit (30 - 60 juta per bulan).

Masyarakat pun masih belum benarbenar paham mengenai penyelenggaraan penyiaran digital. Informasi yang disosialisasikan lebih berisi mengenai keuntungan dari kualitas gambar penyiaran digital. Sementara pemahaman mengenai device-nya (pesawat televisinya) belum dipahami secara baik. Situasi ini sering dimanfaatkan oleh penjual pesawat televisi untuk menghabiskan stok penjualan televisi analog. Sementara informasi yang memadai mengenai spesifikasi televisi yang kompatibel dengan teknologi penyiaran digital sepertinya sengaja tidak diberikan oleh penjual pesawat televisi.

Langkah proses digitalisasi penyiaran televisi di Indonesia sebenarnya terlihat dari adanya Peraturan Menteri Komunikasi dan Informatika Nomor : 27/P/M.Kominfo/8/2008 tentang Uji Coba Lapangan Penyelenggaraan Siaran Televisi Digital, tertanggal 5 Agustus 2008. Dalam peraturan menteri tersebut digariskan uji coba yang akan dilakukan mengubah pola penerimaan televisi pelanggan.Dalamujicobayangdilakukan, ada beberapa hal yang akan dievaluasi, antara lain model penyelenggaraan siaran televisi digital, model regulasi dan kelembagaan, program siaran dan fitur layanan televisi digital, serta kinerja perangkat dan sistem. 
Semua negara harus telah menetapkan tahun migrasi dari siaran analog ke digital. Negara-negara maju di Eropa dan Amerika Serikat bahkan telah mematikan siaran analog (analog switch-off) dan beralih ke siaran digital. Kondisi global menunjukkan bahwa 85\% wilayah dunia sudah mulai mengimplementasikan televisi digital. Jepang melakukan analog switch off pada Juli 2011, Korea Desember
2012, China tahun 2012, UK Oktober 2012, Brunei Juni 2014, Malaysia Desember 2015, Singapura tahun 2015, Thailand dan Pilipina 2015, sementara Vietnam tahun 2020 (http://www.tvdigital.kominfo. go.id). Indonesia merencanakan switch off pada 2012. Namun rencana tersebut sepertinya masih belum jelas mengingat hingga pertengahan 2013, analog switch off belum bisa dilaksanakan.

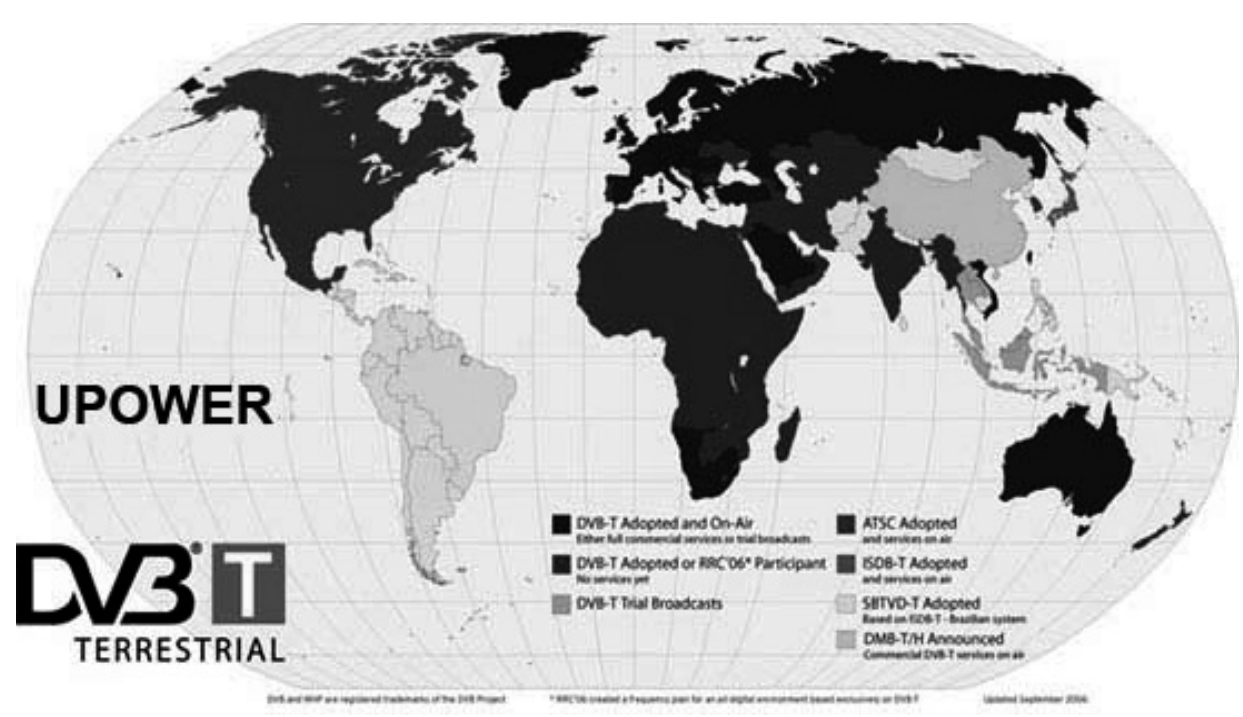

\section{Kondisi Global Implementasi TV Digital}

Sumber: http://www.newupower.com

Dalam roadmap implementasi penyiaran televisi digital, pemerintah merencanakan bahwa tahun 2018 akan dilakukan analog cut off secara nasional. Migrasi setiap zona berbeda. Oleh karena itu, sejak saat ini masyarakat dan para pelaku industri agar mempersiapkan diri untuk melakukan migrasi dari era penyiaran TV analog menuju era penyiaran TV digital.

Pemerintah telah menetapkan tiga tahap yang akan dilalui dalam pelaksanaan migrasi ke penyiaran digital. Tahap pertama akan dimulai 2008 -2012 meliputi tahap uji coba; penghentian izin lisensi baru untuk TV analog setelah beroperasinya penyelenggara infrastruktur TV digital; dimulai lisensi baru untuk penyelenggara infrastruktur TV digital; pemetaan lokasi dimulainya siaran digital dan dihentikannya siaran analog; mendorong industri elektronik dalam negeri dalam penyediaan peralatan penerima TV digital.

Tahap kedua, ditargetkan mulai tahun 2013-2017 dengan kegiatan meliputi penghentian siaran TV analog di kota-kota besar dilanjutkan dengan daerah regional lain; serta intensifikasi penerbitan izin bagi mux operator yang awalnya beroperasi analog ke digital.

Tahap ketiga atau tahap terakhir merupakan periode dimana seluruh siaran 
TV analog dihentikan, siaran TV digital beroperasi penuh pada band IV dan V, dan kanal 49 ke atas digunakan untuk sistem telekomunikasi nirkabel masa depan.

Kementerian Komunikasi dan Informatika

ROADMAP INFRASTRUKTUR TV DIGITAL

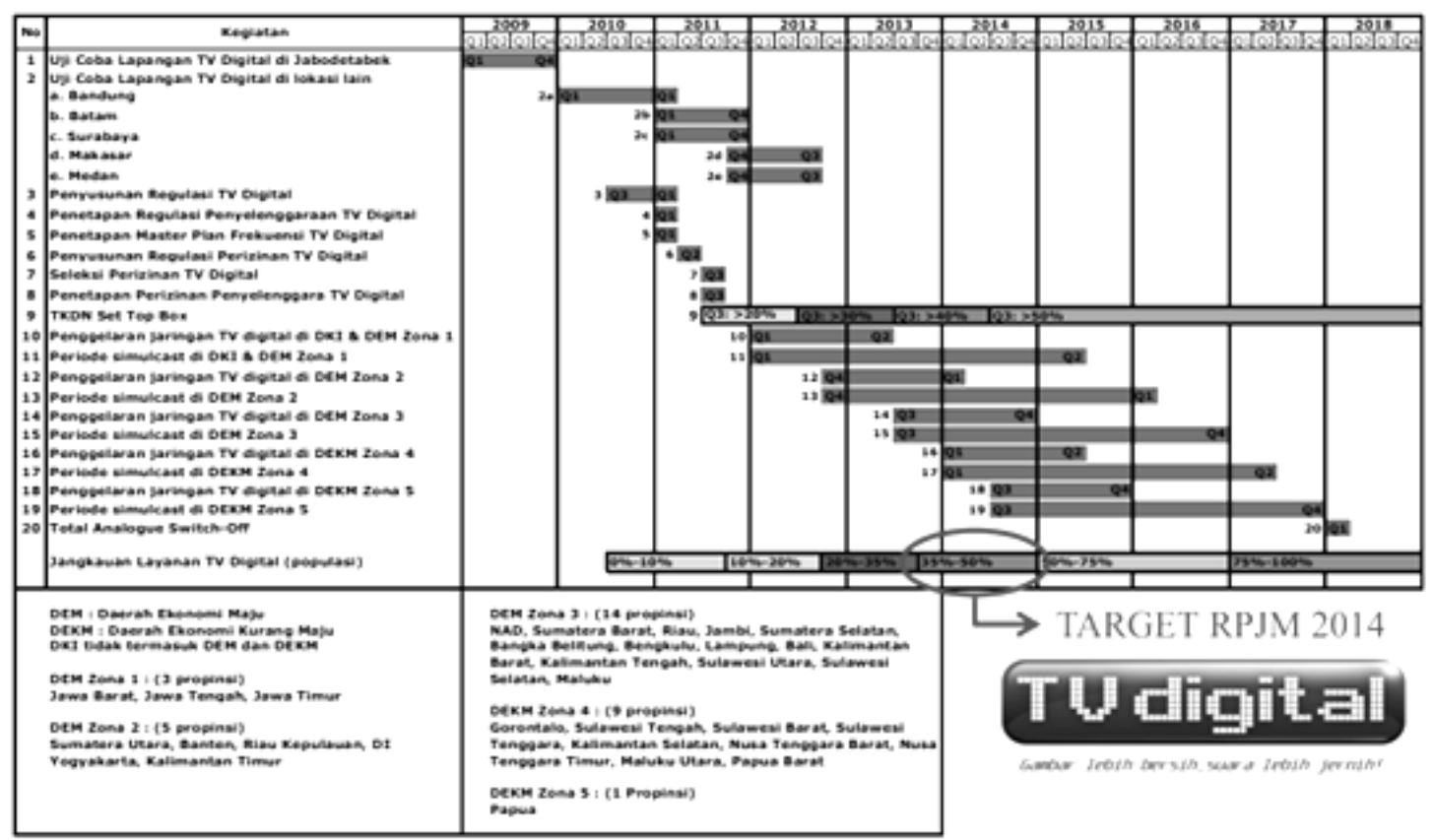

Rangkaian kegiatan yang telah dilaksanakan dalam rangka migrasi siaran analog ke digital di antaranya: soft launching uji coba siaran TV digital di wilayah Jabodetabek oleh Wakil Presiden Jusuf Kalla pada tanggal 13 Agustus 2008 di TVRI. Kemudian secara resmi Presiden Susilo Bambang Yudhoyono melakukan Grand Launching uji coba siaran TV digital pada tanggal20 Mei2009, bertepatan dengan Hari Kebangkitan Nasional yang pelaksanaannya dipusatkan di Studio SCTV Jakarta. Kegiatan uji coba ini merupakan hasil kerjasama antara pemerintah dengan Konsorsium TV Digital Indonesia (KTDI) yang anggotanya terdiri dari 6 TV swasta nasional yang ada di Indonesia (SCTV, TransTV, Trans7, ANTV, TVOne and Metro). Kemudian pada tanggal 3
Agustus 2009, Menteri Kominfo waktu itu, Muhammad Nuh, meresmikan uji coba lapangan siaran digital untuk penerimaan TV bergerak (Mobile TV) yang dilakukan oleh Konsorsium Tren Mobile TV dan Konsorsium Telkom - Telkomsel Indonusa. Pada awal tahun 2010, Menteri Komunikasi dan Informatika, Tifatul Sembiring meresmikan uji coba lapangan penyiaran TV digital untuk wilayah Bandung dan sekitarnya. Pada kegiatan yang dilaksanakan di Sasana Budaya Ganesha tersebut, sebanyak kurang lebih 1000 set top box diberikan kepada masyarakat Bandung sebagai bentuk sosialisasi dan dukungan pemerintah dalam mensukseskan migrasi dari penyiaran TV analog ke TV digital.

Pengalaman di negara lain dalam melakukan migrasi penyiaran analog ke 
digital menunjukkan banyak hal yang harus dipikirkan dan dikelola secara cermat. Di Inggris misalnya, persiapan untuk proses tersebut dilakukan selama 17 tahun dengan mengadakan sekian serial studi mendalam dan simultan tentang perilaku penonton, daya beli masyarakat, cost benefit analysis, aksesibilitas masyarakat terhadap teknologi tersebut, kesiapan teknologi, standardisasi teknologi, sampai pada serangkaian regulasi yang harus dipersiapkan untuk mengaturnya. Bahkan di Inggris, juga dipersiapkan langkah-langkah jangka panjang untuk mengelola pesawat TV analog yang tidak dipakai lagi oleh masyarakat.

Bagi pelaku industri penyiaran, migrasi ke TV digital ini tidak ubahnya seperti meninggalkan rumah sendiri yang sudah dibangun nyaman dan lengkap, untuk selanjutnya harus menyewa rumah orang lain yang harga sewanya tidak murah'. Menurut perhitungan kasar salah satu LP3M, harga sewa mux berkisar 40 juta rupiah setiap bulannya. Artinya broadcaster harus menyediakan dana sebesar itu untuk tetap bisa memancarkan programnya. Bagi pemain besar di dunia penyiaran, dana sebesar ini tentu bukan masalah. Hal ini menjadi masalah ketika ditimpakan kepada TV lokal serta TV komunitas yang sebenarnya mulai bergairah. Permasalahannya adalah bagaimana masa depan TV lokal dan TV komunitas di era digital?

\section{Model Bisnis TV Digital}

Keputusan pemerintah untuk mengadopsi teknologi penyiaran digital menggantikan teknologi televisi analog memang dapat dipahami. Teknologi penyiaran digital telah menjadi tren teknologi global sehingga harus diikuti apabila bangsa Indonesia tidak ingin tertinggal dan terkucil. Sementara itu, data saat ini di Indonesia terdapat 11 TV berizin siaran nasional, 97 TV berizin regional, $30 \mathrm{TV}$ berlangganan (60 persen TV kabel, 20 persen satelit dan 20 persen Terestrial) serta ada sekitar 300 izin baru yang tak terlayani karena sudah tak tersedia lagi kanal TV (Antara News, 2008). Teknologi penyiaran digital kemudian menjadi jawaban yang masuk akal karena teknologi ini dapat memperbanyak kanal televisi.

Teknologi penyiaran televisi digital sangat berbeda dengan teknologi televisi analog yang ada selama ini. Teknologi televisi digital akan mengakibatkan konvergensi media yang semakin tajam dan intensif. Konvergensi tersebut tidak hanya terjadi di dalam aspek teknologinya saja melainkan juga akan terjadi pada tataran pengelolaan dan implikasinya. Konvergensi teknologi penyiaran digital sekaligus akan membawa implikasi sosial, politik dan ekonomi di bidang penyiaran yang sangat siginifikan. Seperti ditegaskan oleh Tadayoni \& Skuby (1999) berikut ini:

Technological innovations like digitalization, audio and video coding technologies computerization and broadband infrastructure, such as cable and satellite networks, make service provision across the sectoral boundaries possible. This Also imposes new political and regulatory challenges and makes re-thinking and re-design of existing regulatory framework for communication anecessity (Reza Tadayoni and Knud Erik Skouby, 1999, Telecommunications Policy 23, 175-199).

Beberapa keuntungan utama dari pemakaian sistem digital pada dunia televisi, adalah : (1) Kualitas transmisi meningkat karena sinyalsinyal digital tidak terlalu rentan terhadap gangguan dan distorsi, (2) berlimpahnya saluran (channel), yang 
dimungkinkan karena adanya kompresi digital (digital compression). Kompresi video memungkinkan untuk mengirim 10 program acara secara serempak pada saluran-saluran yang hanya memiliki satu progam acara. Puncaknya adalah terwujudnya sistem video sesuai permintaan (video on demand) atau secara umum media sesuai permintaan (media on demand) karena banyaknya saluran yang tersedia. (3) Pengawasan oleh pemakai. Melimpahnya pilihan menimbulkan tantangan baru : pemakai menjadi pengawas yang mengendalikan pilihan. Portal, mesin pencari, dan program penyaringan (seperti $V$-Chip) yang memungkinkan menyaring program berbau seksual dan kekerasan, menjadi solusi. (Straubhaar dan LaRose, 2000: 2223).

Selain itu, menurut Weber \& Tom (2007: xvi) keuntungan TV digital bagi konsumen : (1) Peningkatan kualitas video (termasuk reproduksi warna yang lebih baik, resolusi pixel yang lebih tinggi, frame gambar yang progresif. High Definition TV (HDTV) menawarkan lebih dari enam kali resolusi gambar TV analog. (2) Pilihan audio yang banyak, (3) Dapat dikoneksikan dengan personal computer, (3) Tersedianya Random Acces Storage yang memungkinkan akses lebih cepat, (4) Time Shifting (pelanggan dapat mengintervensi siaran, misalnya dengan memberikan respon secara langsung). Adapun keuntungan bagi operator atau distributor : (1) Bandwidth yang lebih efisien, (2) Storage yang berkurang (3) Lebih mudah, termasuk bagi pengiklan untuk mengkreasikan iklannya, (4) Manajemen arsip akan lebih tertata, (5) Tersedianya multi use hardisc. Revolusi TV digital bersamaan dengan revolusi internet juga melahirkan IPTV (Internet Protocol Television) (Weber \& Tom, 2007: xviii).

Selain menjanjikan beragam keuntungan, migrasi teknologi dari analog ke digital membawa konsekuensi yang tidak sederhana, baik dari segi teknis, politis, sosial dan budaya. Pengalaman di Amerika Serikat, televisi digital membawa perubahan fundamental pada bagaimana TV diproduksi, diedit, dan disiarkan. TV digital mempersyaratkan perubahan infrastruktur secara massif untuk pembuatan dan transmisi sinyal digital, termasuk juga penggantian pesawat TV analog ke pesawat digital. Di AS lebih dari 200 juta pesawat TV analog harus diganti. Transisi dari analog ke digital dimulai tahun 1990, era TV analog diputuskan untuk diakhiri oleh The Federal Communication Commision pada Desember 2008 (Weber \& Tom, 2007: xvii).

Kompleksitas persoalan migrasi teknologi digital pada televisi, dipengaruhi oleh aspek bisnis industri televisi itu sendiri. Menurut (Drury, et all, 2001:14-18), bisnis televisi dipengaruhi oleh (1) infrastruktur penyiaran, (2) regulasi, dan (3) masalah komersial. Infrastruktur penyiaran terdiri dari beberapa bagian yang saling terkait, yaitu : (1) program dan produksinya, (2) kompilasi program dalam jadwal iklan, (3) jaringan transmisi, (4) emisi atau radiasi sinyal dari transmitter terrestrial atau satelit, dan (5) infrastruktur industri televisi.

Regulasi dibutuhkan untuk mengontrol akses terhadap spectrum yang terbatas dan menjamin bahwa spectrum itu digunakan oleh orang atau organisasi yang bertanggung jawab terhadap kepentingan publik. Regulasi diterapkan dengan pendekatan yang berbeda-beda, misalnya pendekatan 
yang lebih dikendalikan kepentingan komersial seperti di AS, atau kepentingan publik di Eropa secara umum, atau pendekatan lain yang lebih menekankan kontrol negara dan lembaga penyiaran dijalankan untuk kepentingan politik . Efek teknologi digital yang membawa konvergensi di antara media penyiaran, telekomunikasi, dan industri komputer, menyebabkan badan-badan regulator mendapat tantangan karena munculnya tumpang tindih jurisdiksi dan hubungan di antara mereka. Masalah komersial selalu muncul karena broadcasting adalah bisnis. Kepentingan ekonomi selalu dihadapkan dengan kepentingan sosial publik. (Drury, et all, 2001: 17).

Aspek bisnis televisi digital menjadi sentral perbincangan dalam migrasi tekologi tersebut, sehingga perancangan model bisnis yang paling tepat diterapkan menjadi agenda besar. Digital Multimedia Broadcasting (DMB) sebagai produk teknologi baru tidak hanya dilihat sebagai produk teknologi semata, tetapi penting untuk dilihat dari aspek teknis, ekonomis dan regulasi. Munculnya DMB telah mempengaruhi generasi lingkungan jaringan masa depan (a next generation networkenvironment). Shin(2006) mengkaji bagaimana DMB menjadi pemicu dalam perubahan stuktur industri, pasar dan politik di Korea. Selain itu ditelaah juga apa faktor-faktor apa yang menyebabkan cepatnya perkembangan DMB di Korea. DMB Korea merupakan hasil dari strategi proaktif operator telekom dan kebijakan pemerintah untuk mendukung strategi itu. Perspektif socio-technical menyediakan framework yang kuat karena bersifat integatif dan holistik.

Perspektif socio-technical ini didasari oleh teori social construction yang melihat persoalan teknologi sebagai persoalan teknis dan sosial sekaligus. Hubungan antara teknologi dan masyarakat, antara artefak teknis dan wacana yang melingkupinya adalah hal penting bagi teknologi sepeti DMB untuk didisain, dikembangkan dan digunakan. Sawyer dalam Shin (2006) menyebutkan bahwa socio-technical perspective adalah kerangka kerja yang baik untuk menginvestigasi hubungan yang kompleks antara teknis dan proses sosial sebagai fenomena yang serius untuk mempertimbangkan asepek detail teknis dan sosial dalm teknologi informasi. Pendekatan sistem sociotechnical digunakan secara luas dalam mendisain sistem kerja dan mendasari sub sistem teknis dan sistem sosial. Kedua sub sub sistem ini bersifat interdependent dan jika digabungkan dalam sebauh disain maka keseluruhan sistem akan berjalan optimal (Sitter et al dalam Shin, 2006).

Teori socio-technical memberi kontribusi dalam memahami interaksi sosial dan artefak teknis (Shin, 2005). Teori ini digunakan juga dalam redesain organisasi (Pasmore et al dalam Shin, 2006). Tujuan teori ini adalah mengembangkan desain organisasi secara optimal yang memungkinkan komponen yang ada bekerja sama secara baik. Komponen itu adalah : sub sistem sosial, sub sistem teknik, dan sub sistem lingkungan. Dengan tiga komponen ini perspektif socio technical digunakan untuk menginvestigasi integrasi teknologi, proses, sumber daya manusia, dan struktur organisasi (Posmore dalam Shin, 2006).

Teori Socio-technical system melihat implementasi sebuah produk teknologi dalam tiga subsistem yaitu : sub sistem teknis (infrastruktur, peralatan, aplikasi dan layanan), sub sistem sosial (pasar, pelanggan, dan industri), dan lingkungan (regulasi, kebijakan dan masyarakat). Studi yang dilakukan Shin (2006) melihat 
hubungan antara subsistem-subsistem itu untuk melihat dinamika perubahan teknologi dengan mencermati hubungan interaksi sosial dan pilihan teknologi. Dalam konteks ini, televisi digital dapat dilihat sebagai sebuah artefak sosioteknis yang memiliki keterkaitan dengan kultur, politik, industri dan masyarakat. Masing-masing sub sistem teknis, sosial dan lingkungan itu dijelaskan untuk menjadi referensi faktor lain. Sehingga teknologi tidak dapat dilihat sebagai teknologi semata.

Berdasarkan studi Shin (2006), pengalaman pengembangan Digital Multimedia Broadcasting di Korea menunjukkan bahwa regulasi seolah menjadi kembali ke belakang seperti di masa awal pembangunan. Karena ketiadaan konsep yang jelas tentang konvergensi dan kebijakan yang relevan, regulasi dan layanan konvergensi, DMB di Korea menghadapi overlaping regulasi di satu kasus dan ketiadaan regulasi di kasus yang lain. Regulator penyiaran Korea memainkan peran penting untuk regulasi DMB seperti lisensi, spektrum, dan regulasi lainnya. Socio-technical perspective memperlihatkan aspek DMB dan interaksi dinamis antara technology, service, market, regulation, dan pengguna. Keseluruhan pengembangan DMB di Korea memperlihatkan bahwa teknologinya relatif dikembangkan, tetapi aspek lain seperti pasar, pengguna dan regulasi tidak dikembangkan secepat pengembangan teknologi.

Teknologi penyiaran digital yang mampu menampung siaran lebih banyak, membuka peluang untuk munculnya bisnis yang men-support untuk menopang kemungkinan siaran yang muncul. Gambaran sederhananya di Zona 6 Jateng DIY. Di zona ini akan kebagian enam kanal frekuensi. Dalam teknologi ini setiap frekuensi bisa menampung 12 siaran. Artinya apabila berjalan secara optimal, di wilayah ini saja akan ada 72 stasiun TV yang beroperasi. Untuk memenuhi kebutuhan siaran stasiun sebanyak itu membutuhkan suporting Industry seperti Production House (PH). Oleh karenanya model bisnis TV digital bisa digambarkan dalam gambar berikut.

\section{Rantai Produksi TV Digital TT}

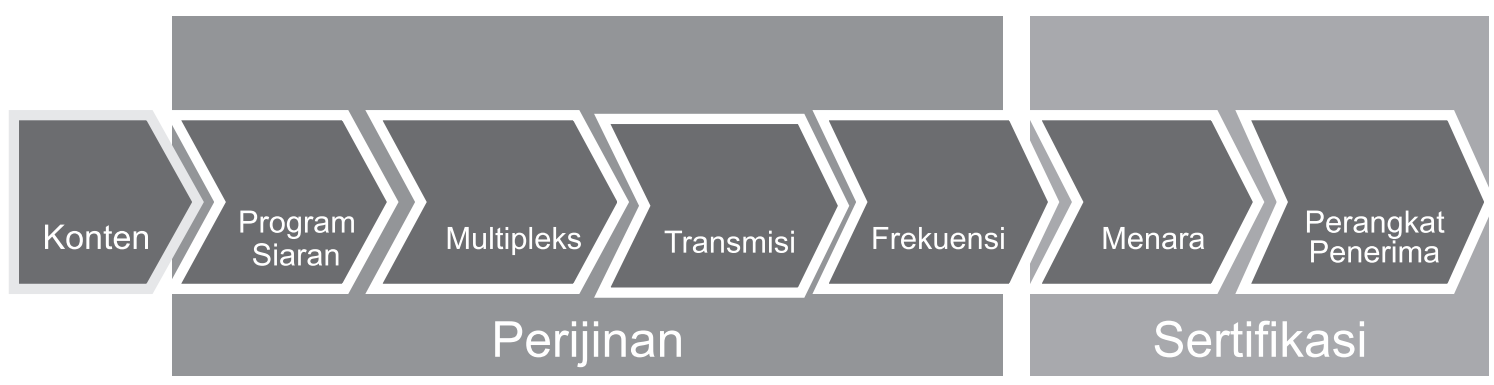

Darigambar diatas tampak memungkinkan munculnya pemain-pemain baru dalam bisnis penyiaran televisi digital terestrial. Pemain-pemain baru itu adalah penyedia konten, penyelenggara program siaran atau Lembaga Penyiaran Penyelenggara Program Siaran (LP3S), multiplekser/ Lembaga Penyiaran Penyelenggara Penyiaran Multipleksing (LP3M) dan penyedia menara dan pe- 
rangkat. Semakin banyaknya pemain dalam bisnis penyiaran digital terestrial ini menjadi semakin berkurang kemungkinan monopoli dari hulu sampai ke hilir bisnis televisi. Idealnya dengan berkurangnya monopoli secara alamiah ini akan meningkatkan kinerja bisnis dalam industri televisi digital.

Konten, akan diproduksi oleh penyedia jasa produksi content siaran televisi. Penyedia jasa produksi konten ini bisa individu ataupun kelompok. Program Siaran, merupakan gabungan dari kontent-konten yang disusun berdasarkan jadwal tertentu dan disiarkan. Multiplekser, merupakan sistem perangkat untuk menyalurkan beberapa program siaran dari para Penyelenggara Program Siaran yang kemudian dipancarkan kepada masyarakat/penonton melalui suatu perangkat transmisi. Transmisi merupakan perangkat untuk memancarkan siaran dari multiplekser kepada masyarakat/penonton dengan menggunakan media spectrum frekuensi radio. Perangkat penerima, dapat berupa pesawat penerima televisi digital atau pesawat penerima televisi analog yang dilengkapi dengan set top box (STB).

Dilihat model bisnisnya, pelaku utama dalam sistem penyiaran semacam itu terletak pada Lembaga Penyiaran Penyelenggara Program Siaran (LP3S) dan Lembaga Penyiaran Penyelenggara Penyiaran Multipleksing (LP3M). Dari keduanya,LP3M lah yang memiliki 'kuasa' dalam penyelenggaraan siaran. Oleh karenanya tidak mengherankan ketika proses pelelangan penyelenggara multiplekser menjadi isu penting dalam proses migrasi TV digital. Nantinya semua LP3S harus menyewa LP3M agar dapat menyelenggarakan siaran. Karena secara bisnis lebih visible dan menjanjikan, isu untuk menjadi LP3M lebih seru daripada isu tentang LP3S.hingga saat ini isu untuk menjadi LP3S berhembus tidak sekencang LP3M.

Pembagian blok dalam model gambar di atas diharapkan akan menghasilkan efisiensi biaya (cost), fokus atas bisnis sesuai dengan fungsi-fungsinya dan terjadi kompetisi yang sehat antara para pemainnya. Penyelenggara program siaran dan penyelenggara Multiplekser yang juga sebagai pemegang Hak Penggunaan Frekuensi memiliki lisensi tersendiri dan tidak harus dimiliki oleh satu badan hukum tertentu.

Izin penyelenggaraan multiplekser/ transmisi akan diberikan melalui mekanisme seleksi atau lelang (beauty contest). Izin penyelenggara Program Siaran berlaku untuk wilayah jangkauan siaran sesuai wilayah jangkauan siaran yang tercantum dalam IPP setiap Penyelenggara Program Siaran, sedangkan izin Penyelenggara Multiplekser berlaku untuk satu zona layanan.

Dalam satu wilayah jangkauan siaran, Penyelenggara Multipleks hanya boleh menggunakan satu kanal frekuensi. Penyelenggara Program Siaran (PS) Swasta hanya boleh menyiarkan satu program siaran yang disalurkan melalui Penyelenggara Multipleks yang beroperasi dalam wilayah jangkauan siaran sebagaimana tercantum pada IPP yang dimiliki PS tersebut. Tidak boleh ada kepemilikan silang pada Penyelenggara Multipleks dalam 1 (satu) zona layanan.

Tujuh dari 15 zona layanan telah dilakukan pelelangan. Pemenang pada masing-masing zona tersebut dalam tabel berikut : 


\section{Hasil Seleksi Lembaga Penyiaran Penyelenggara Penyiaran Multipleksing Pada Penyelenggaraan Penyiaran Televisi Digital Terestrial Penerimaan Tetap Tidak Berbayar (Free to Air)}

\begin{tabular}{|c|c|c|}
\hline Zona Layanan & Perusahaan & Nama Sebutan \\
\hline \multirow{5}{*}{$\begin{array}{l}\text { zona layanan } 1 \\
\text { (Aceh dan Sumatera Utara) }\end{array}$} & PT. RCTI Lima Belas Aceh & RCTI Network \\
\hline & $\begin{array}{l}\text { PT. Cakrawala Andalas Televisi Medan } \\
\text { dan Batam }\end{array}$ & ANTV Medan \\
\hline & PT. Trans7 Medan Palembang & Trans7 Medan \\
\hline & PT. Media Televisi Banda Aceh & Metro TV Aceh \\
\hline & PT. Indosiar Medan Televisi & Indosiar Medan \\
\hline \multirow{5}{*}{$\begin{array}{l}\text { zona layanan } 14 \\
\text { (Kalimantan Timur dan } \\
\text { Kalimantan Selatan) }\end{array}$} & PT. Trans7 Pontianak Samarinda & Trans7 Samarinda \\
\hline & PT. GTV Tujuh & Global TV \\
\hline & $\begin{array}{l}\text { PT. Lativi Mediakarya Manado dan Sa- } \\
\text { marinda }\end{array}$ & TVOne Samarinda \\
\hline & PT. Media Televisi Banjarmasin & Metro TV Kalsel \\
\hline & PT. Surya Citra Multikreasi & SCTV Banjarmasin \\
\hline \multirow{5}{*}{$\begin{array}{l}\text { Zone Layanan } 4 \\
\text { (DKI Jakarta dan Banten) }\end{array}$} & PT Banten Sinat Dunia Televisi & BSTV \\
\hline & PT Lativi Media Karya & TVOne \\
\hline & PT Media Televisi Indonesia & Metro TV \\
\hline & PT Surya Citra Televisi & SCTV \\
\hline & PT Televisi Transformasi Indonesia & Trans TV \\
\hline \multirow[t]{5}{*}{$\begin{array}{l}\text { Zone Layanan } 5 \\
\text { (Jawa Barat) }\end{array}$} & $\begin{array}{l}\text { PT Cakrawala Andalas Televisi Bandung } \\
\text { dan Bengkulu }\end{array}$ & ANTV Bandung \\
\hline & PT Indosiar Bandung Televisi & Indosiar Bandung \\
\hline & PT Media Televisi Bandung & Metro TV Jabar \\
\hline & PT RCTI Satu & RCTI Network \\
\hline & PT Trans TV Yogyakarta Bandung & Trans TV Bandung \\
\hline \multirow{5}{*}{$\begin{array}{l}\text { Zone Layanan } 6 \\
\text { (Jawa Tengah dan } \\
\text { Yogyakarta) }\end{array}$} & PT GTV Dua & Global TV \\
\hline & PT Indosiar Televisi Semarang & Indosiar Semarang \\
\hline & PT Lativi Mediakarya Semarang-Padang & TVOne Semarang \\
\hline & PT Media Televisi Semarang & $\begin{array}{l}\text { Metro TV Jawa } \\
\text { Tengah }\end{array}$ \\
\hline & PT Trans TV Semarang Makassar & Trans TV Semarang \\
\hline \multirow{5}{*}{$\begin{array}{l}\text { Zone Layanan } 7 \\
\text { (Jawa Timur). }\end{array}$} & PT Cakrawala Andalas Televisi & ANTV \\
\hline & PT Global Informasi Bermutu & Global TV \\
\hline & PT Media Televisi Indonesia & Metro TV \\
\hline & PT Surya Citra Televisi & SCTV \\
\hline & PT Televisi Transformasi Indonesia & Trans TV \\
\hline \multirow{3}{*}{$\begin{array}{l}\text { Zone Layanan } 15 \\
\text { (Kepulauan Riau). }\end{array}$} & PT RCTI Sepuluh & RCTI Network \\
\hline & PT Surya Citra Pesona Media & SCTV Batam \\
\hline & PT Trans TV Batam Kendari & Trans TV Batam \\
\hline
\end{tabular}


Tabel tersebut menunjukkan bahwa pemenang penyelenggara multiplexing adalah pelaku lama yang saat ini menguasai pertelevisian nasional. Hampir bisa dipastikan bahwa di era digital nantinya tetap akan dikuasai oleh industri pertelevisian besar, sehingga harapan untuk adanya diversity of content maupun ownership tetap kalah oleh mekanisme liberal semacam ini.

\section{Prospek TV Lokal dan TV Komunitas}

Data belanja iklan media di Indonesia sepanjang tahun 2012 menurut AC Nielsen mengalami pertumbuhan sebesar 20\% dibandingkan dengan tahun sebelumnya. Nilainya mencapai Rp 87 triliun, dengan media televisi mendominasi $64 \%$ dari total belanja iklan, diikuti surat kabar sebesar 33\%, dan 3\% di majalah atau tabloid. Selain menjadi pangsa belanja iklan terbesar, belanja iklan di media televisi juga mengalami pertumbuhan sebesar $24 \%$, tertinggi dibandingkan media cetak seperti surat kabar dan majalah yang hanya tumbuh $14 \%$ dan $7 \%$.

Angka $64 \%$ untuk televisi tersebut merupakan angka kotor, belum dikurangi diskon atau harga khusus. Angka yang benar-benar masuk adalah sekitar 36\%. Untuk TV lokal lebih kecil lagi. Biaya investasi yang cukup besar, biaya sewa yang tidak sedikit serta sistem produksi yang harus berstandar digital menjadikan lembaga penyiaran yang bermodal paspasan tidak akan mampu bersaing di era digital. Praktis peralatan yang dimiliki sekarang yang msih berbasis analog tidak bisa digunakan lagi. Broadcaster harus berinvestasi untuk memenuhi standar digital.

Realitas semacam ini dikeluhkan oleh TV lokal hampir di seluruh penjuru tanah air. Menjamurnya TV lokal yang sepertinya sedang berusaha untuk meramaikann industri pertelevisian, sepertinya harus tiarap lagi. Ketika TV lokal saat ini sedang menemukan bentuknya dan mulai bisa bertahan, harus menerima kenyataan merubah model bisnis dari yang selama ini dijalankan. Asosiasi TV Lokal menilai, adanya kewajiban menyerahkan sejumlah uang jaminan sampai miliaran rupiah merupakan hal yang memberatkan bagi TV lokal. Pada tahap prakualifikasi, calon peserta LP3M wajib menyerahkan uang jaminan Rp 1 miliar. Kemudian, jika lulus tahap prakualifikasi, calon peserta LP3M menyerahkan jaminan lagi sebesar Rp 7 miliar agar bisa masuk proses kualifikasi. Selain itu, ATVLI mengeluhkan standar infrastruktur yang harus digunakan sebuah lembaga siaran yang wajib disesuaikan dengan standar penyiaran pemerintah (Kontan.co.id diakses tanggal 22 Mei 2013).

Biaya investasi yang cukup tinggi menjadikan TV lokal kesulitan untuk beradaptasi dengan teknologi digital. Jogja TV mengaku, untuk bertahan pada situasi sekarang saja masih berat. Pendapatan baru mampu menutup biaya operasional. Untuk berinvestasi tentunya membutuhkan suntikan dana dari pihak lain. Sementara dilihat dari prospek pendapatan juga dirasakan masih berat. Selama TV nasional masih mendominasi siaran di daerah, upaya TV lokal untuk merebut iklan akan berat. Untuk mengatasi kendala investasi yang mahal ini, teknologi yang dikembangkan sepertinya mengarah ke televisi satelit dengan menggunakan dekoder.

Nasib yang sama akan menimpa TV komunitas. Untuk menyewa multiplekser seharga 40 juta rupiah setiap bulan sangat 
mustahil dilakukan. Sementara untuk mengharapkan diberikannya frekuensi secara gratis juga tidak mungkin. Kondisi ini yang sekarang menghantui penyelenggara TV Komunitas. Salah satu alternatif yang muncul adalah melakukan siaran bersama dalam satu mux dengan sharing waktu. Artinya beberapa TV Komunitas menyewa satu mux untuk digunakan bersama-sama. Namun masalah yang akan muncul adalah alokasi waktunya.

Dari dilema ini, yang menjadi permasalahan selanjutnya adalah apakah era TV digital akan menambah dan meningkatkan jumlah industri TV atau sebaliknya justru memberangus penyiaran yang sekarang sudah ada.

\section{Simpulan}

Teknologi penyiaran digital merupakan era yang baru baik dari segi produksi, distribusi maupun bisnis. Dari aspek produksi, peralatan pendukung teknologi ini adalah berbasis digital. Broadcaster yang sekarang ini menggunakan teknologi analog, mau tidak mau harus berinvestasi untuk peralatan digital. Aspek ini sepertinya bukan mejadi masalah besar dalam dunia penyiaran di Indonesia, karena $80 \%$ program sudah berbasis digital. Aspek kedua masalah distribusi berkaitan dengan device penerimanya. Saat ini masyarakat belum paham betul mengenai device penerima siaran digital. Sehingga ketika belanja pesawat televisi aspek teknologi ini tidak menjadi pertimbangan. Ketiga masalah bisnis. Model bisnis televisi digital titik sentral industrinya adalah pelaksana multiplekser. Untuk membangun multiplekser membutuhkan modal yang besar. Sementara pelaksana broadcasting-nya harus menyewa pemilik multiplekser tersebut.

Bagi broadcaster besar seperti yang ada sekarang ini, investasi TV digital hampir bukan merupakan masalah. Namun bagi TV lokal dan TV komunitas investasi sebesar itu merupakan masalah yang serius. Biaya sewa multiplekser masih menunggu kebijakan pemerintah. Namun berdasarkan perhitungan bisnis pemenang pelaksana multipleksing, sewanya berkisar 40 juta setiap bulan. Tanpa keberpihakan pemerintah, jelas TV lokal dan TV komunitas tidak akan mampu menyewa. Diversity of content dan diversity of ownership hanya menjadi sebuah wacana tanpa ujung. Sekali lagi perlu campur tangan pemerintah diharapkan untuk menyelamatkan pertelevisian nasional dari dominasi kuasa modal.

\section{Daftar Pustaka}

Braet, Olivier, Ballon, Pieter, (2008), Cooperation Models for Mobile Television in Europe, Telematics and Informatics 25 (2008), 216-236

Drury, Godon, Markarian, Garik, Pickavance, Keith, (2001), Coding and Modulation for Digital Television, Kluwer Academic Publishers, Norwell Massachusetts

Shin, Dong H, (2006), Socio-Technical Challenges in The Development ofDigital Multimedia Broadcasting : A Survey of Korean Mobile Television Development, Technological Forecasting and Social Change, 73 (2006), 1144-1160

Strabhaar, LaRose, (2000), Media Now, Communication Media in Information Age, Wadsworth, Belmont USA. 
Tayadoni, Reza, Skuby, Knud, Erik, (1999), Terrestrial Digital Broadcasting: Convergence and Its Regulatory Implications, Telecommunications Policy 23 (1999) : 175-199
Weber,Joseph, Newberry, Tom, (2007), IPTV Crash Course, McGraw Hill, New York: 